\title{
The role of methane in future climate strategies: mitigation potentials and climate impacts
}

\author{
Mathijs Harmsen ${ }^{1,2}$ (D) Detlef P. van Vuuren ${ }^{1,2} \cdot$ Benjamin Leon Bodirsky $^{3}$. \\ Jean Chateau ${ }^{4}$. Olivier Durand-Lasserve ${ }^{4}$ - Laurent Drouet ${ }^{5}$. Oliver Fricko ${ }^{6}$. \\ Shinichiro Fujimori ${ }^{7,8}$ - David E. H. J. Gernaat ${ }^{1,2}$ - Tatsuya Hanaoka ${ }^{8}$. \\ Jérôme Hilaire ${ }^{3,9}$ - Kimon Keramidas ${ }^{10}$. Gunnar Luderer ${ }^{3}$. Maria Cecilia P. Moura ${ }^{11}$. \\ Fuminori Sano ${ }^{12}$. Steven J. Smith ${ }^{11}$ - Kenichi Wada ${ }^{12}$
}

Received: 23 January 2018 / Accepted: 10 April 2019 /Published online: 24 May 2019

(C) The Author(s) 2019

\begin{abstract}
This study examines model-specific assumptions and projections of methane $\left(\mathrm{CH}_{4}\right)$ emissions in deep mitigation scenarios generated by integrated assessment models (IAMs). For this, scenarios of nine models are compared in terms of sectoral and regional $\mathrm{CH}_{4}$ emission reduction strategies, as well as resulting climate impacts. The models' projected reduction potentials are compared to sector and technology-specific reduction potentials found in literature. Significant cost-effective and nonclimate policy related reductions are projected in the reference case (10-36\% compared to a "frozen emission factor" scenario in 2100). Still, compared to 2010, $\mathrm{CH}_{4}$ emissions are expected to rise steadily by $9-72 \%$ (up to 412 to $654 \mathrm{Mt} \mathrm{CH}_{4}$ year). Ambitious $\mathrm{CO}_{2}$ reduction measures could by themselves lead to a reduction of $\mathrm{CH}_{4}$ emissions due to a reduction of fossil fuels $(22-48 \%$ compared to the reference case in 2100). However, direct $\mathrm{CH}_{4}$ mitigation is crucial and more effective in bringing down $\mathrm{CH}_{4}$ (50-74\% compared to the reference case). Given the limited reduction potential, agriculture $\mathrm{CH}_{4}$ emissions are projected to constitute an increasingly larger share of total anthropogenic $\mathrm{CH}_{4}$ emissions in mitigation scenarios. Enteric fermentation in ruminants is in that respect by far the largest mitigation bottleneck later in the century with a projected 40-78\% of total remaining $\mathrm{CH}_{4}$ emissions in 2100 in a strong $\left(2{ }^{\circ} \mathrm{C}\right)$ climate policy case.
\end{abstract}

\section{Introduction}

Studies have shown that anthropogenic non- $\mathrm{CO}_{2}$ greenhouse gas (GHG) emissions, predominantly methane $\left(\mathrm{CH}_{4}\right)$ and nitrous oxide $\left(\mathrm{N}_{2} \mathrm{O}\right)$ from agriculture, are expected to represent an increasingly

Electronic supplementary material The online version of this article (https://doi.org/10.1007/s10584-01902437-2) contains supplementary material, which is available to authorized users.

This article is part of a Special Issue reporting results from the "Energy Modeling Forum (EMF)-30 Study on ShortLived Climate Forcers (SLCF) and Air Quality" edited by John Weyant, Steven J Smith, and Zbigniew Klimont

Mathijs Harmsen

j.h.m.harmsen@uu.nl

Extended author information available on the last page of the article 
larger share of total GHG emissions in stringent mitigation (Clarke et al., 2014; Gernaat et al., 2015) This makes non- $\mathrm{CO}_{2} \mathrm{GHG}$ a possible obstacle in achieving the $2^{\circ}$ to $1.5^{\circ} \mathrm{C}$ climate target as agreed upon in the 2015 Paris Accords (UNFCCC, 2015). However, there is a large range in non- $\mathrm{CO}_{2}$ GHG projections, arising from uncertainty about emission levels when unabated and the availability and cost of technologies to mitigate emissions from specific sources. Understanding this uncertainty is crucial when determining optimal mitigation strategies.

As part of the Energy Modeling Forum (EMF)-30 Study on Short-Lived Climate Forcers and Air Quality (EMF, 2019), which examines the potential contribution of short-lived climate forcers (SLCFs) to climate policy, this study contributes a detailed analysis of $\mathrm{CH}_{4}$ emissions and emission reductions. With a shorter lifetime than $\mathrm{CO}_{2}, \mathrm{CH}_{4}$ emission reductions can more effectively contribute to climate mitigation in a short timeframe, but also long-term $\mathrm{CH}_{4}$ forcing is substantially more dependent on future emission levels rather than present-day emissions. The specific focus on $\mathrm{CH}_{4}$ is motivated by the expectation that it will continue to be the most influential GHG after $\mathrm{CO}_{2}$ (Gernaat et al., 2015; Saunois et al., 2016), which demands for a more in-depth assessment.

The scenario analysis is based on a multi-model comparison approach with nine integrated assessment models (IAMs), which is to our knowledge the widest set of models employed to provide a consistent range of projections dedicated to this subject. The scenarios allow for a comprehensive analysis of multiple aspects of potential $\mathrm{CH}_{4}$ mitigation in future scenarios:

1) Assessing cost-effective and non-climate policy related improvements in $\mathrm{CH}_{4}$ emission intensity (i.e., the use of fugitive $\mathrm{CH}_{4}$ emissions as an energy source, air quality measures and net zero, or negative cost measures). This provides a better understanding of the baseline case without climate policy and starting point for further $\mathrm{CH}_{4}$ reductions.

2) Exploring the potential range in $\mathrm{CH}_{4}$ emission projections and resulting climate effects, from no climate policy to a stringent climate policy case.

3) Disentangling direct $\mathrm{CH}_{4}$ mitigation and indirect mitigation as a result of $\mathrm{CO}_{2}$ mitigation policy (the latter through a decrease in fossil fuel production, leading to less fugitive $\mathrm{CH}_{4}$ emissions).

In order to further understand what will be main bottlenecks and opportunities in limiting future $\mathrm{CH}_{4}$ emissions, the projected sectoral emission reductions are compared to maximum emission reductions found in literature. Differences in reduction potentials are, where possible, traced back to model-specific assumptions and insights from literature. As such, this analysis provides potential real-world implications for future climate policy and insights in required technological changes.

\section{Methods}

\subsection{Scenario analysis}

Nine models have taken part in a multi-integrated assessment model (IAM) scenario comparison, ${ }^{1}$ with a consistent experimental setup across the models: AIM/CGE, DNE21+, ENVLinkages, GCAM, IMAGE, MESSAGE-GLOBIOM, POLES, REMIND, and WITCH-

\footnotetext{
${ }^{1}$ The scenario analysis has been performed as part of the 30th Energy Modelling Forum (EMF30), an international collaboration project with the goal of understanding the potential role of short-lived climate forcer (SLCF) mitigation in climate policy EMF (2017) EMF 30: short lived climate forcers/air quality.
} 
GLOBIOM (see section S1 in the Supplement). The IAMs have been widely used in climate policy research (e.g., Kriegler et al., 2014; Riahi et al., 2017; Tavoni et al., 2014; Van Vuuren et al., 2011) and include comprehensive global representations of the human economic system, its interaction with the natural system and associated emissions. Assumptions on the representation of mitigation options, technological, sectoral and regional detail, and the level of foresight for finding optimal policy strategies vary widely across the models. As such, the models cover a broad section of the solution space for reaching climate targets. All models represent the main $\mathrm{CH}_{4}$ sources: fossil energy production, agriculture, and waste, either as aggregated sector emissions or on a sub-sectoral level. These sources represented $89 \%$ of total anthropogenic $\mathrm{CH}_{4}$ emissions in 2012 (Saunois et al., 2016). Other sources (industrial processes, energy demand/fuel burning, deforestation, and international shipping and aviation) are occasionally missing in some of the models, in which case these models are not used in the analysis of the source concerned.

The following scenarios have been analyzed:

- "Reference," a no climate policy scenario with default model improvements in $\mathrm{CH}_{4}$ emission factors and default long-term air-pollutant emission controls. Cost-effective (i.e., leading to net zero or negative system costs) and non-climate policy related mitigation options are allowed; i.e., increased use of fugitive $\mathrm{CH}_{4}$ emissions for cost-effective energy production, reducing $\mathrm{CH}_{4}$ emissions as a safety risk, or as part of future air quality policy). The scenario is based on SSP2, a widely used model setup with middle-of-the-road development assumptions (Riahi et al., 2017).

- "Fzn-CH4," a diagnostic scenario analogous to Reference, but with constant ("frozen") $\mathrm{CH}_{4}$ emission factors from 2010 onward, assuming no emissions control advancements beyond 2010. The scenario is used to diagnose the amount of emission control in the reference scenario.

- "ClimPolicy," a cost-optimal (i.e., minimized policy costs) $2{ }^{\circ} \mathrm{C}$ climate policy scenario, with a global cumulative energy and industry $\mathrm{CO}_{2}$ emissions constraint of $1000 \mathrm{GtCO}_{2}$ from 2011 to 2100. This budget corresponds to the upper end of emission budgets of scenarios in the $430-480$ ppm $\mathrm{CO}_{2}$ category of likely $2{ }^{\circ} \mathrm{C}$ scenarios. All GHGs are targeted together in a "multi-gas" approach with the same model-specific $\mathrm{CO}_{2}$ price and 100 -year global warming potential metric to acquire non- $\mathrm{CO}_{2}$ emission prices (see Table $\mathrm{S} 1.1$ in the Supplement).

- "ClimPolicy- $\mathrm{CH}_{4}$ only," a diagnostic scenario to isolate the effect of direct ("end-ofpipe") $\mathrm{CH}_{4}$ mitigation. The $\mathrm{CH}_{4}$ price from ClimPolicy is applied to $\mathrm{CH}_{4}$ reduction measures only, with no price applied to $\mathrm{CO}_{2}$ or any other GHG (note that under a $\mathrm{CH}_{4}$ price, some structural changes can occur that do affect other GHGs, e.g., a higher natural gas price can reduce natural gas production, which lowers $\mathrm{CO}_{2}$ emissions).

- "ClimPolicy- $\mathrm{CO}_{2}$ only," a diagnostic scenario to isolate the indirect $\mathrm{CH}_{4}$ mitigating effect of $\mathrm{CO}_{2}$ mitigation policy. It has the same $\mathrm{CO}_{2}$ budget as ClimPolicy, but no price is applied to any other GHGs.

Using the years 2050 and 2100 as a benchmark, the scenarios are compared in terms of (1) source-specific, region-specific, and total $\mathrm{CH}_{4}$ emissions and reductions, and (2) climate

\footnotetext{
${ }^{2}$ This scenario is slightly different from the EMF30 scenario "CH4-only" which assumes a constant $\mathrm{CH}_{4}$ price between 2030 and 2100. In all models, that scenario leads to higher emissions $(5-76 \%$, average $=32 \%)$ in 2100 . For better comparison with ClimPolicy and to assess the deepest $\mathrm{CH}_{4}$ reductions, $\mathrm{ClimPolicy}^{-\mathrm{CH}_{4}}$ only is used in this study.
} 
impacts: $\mathrm{CH}_{4}$ radiative forcing (RF), total $\mathrm{RF}$, and global mean temperature (GMT). The climate parameters have been assessed using the same climate model for all the models and scenarios: MAGICC6 (Meinshausen et al., 2011), to ensure consistency in the climate-related results. In terms of its $\mathrm{CH}_{4}$ forcing projections, this simple climate model fits well within the range of projections of complex climate models it emulates (Harmsen et al., 2015). The scenarios are compared to provide insight in the following:

\begin{tabular}{lc}
\hline Comparison & Insight \\
Fzn-CH4, Reference & Emission and climate effect of autonomous, cost-effective and \\
& non-climate policy related improvements in $\mathrm{CH}_{4}$ emission intensity \\
& (i.e., air quality measures and net zero or negative cost measures). \\
Reference, ClimPolicy & $\begin{array}{c}\text { Sector and region-specific as well as total } \mathrm{CH}_{4} \text { emissions with and without } \\
\text { climate policy. Total range in } \mathrm{CH}_{4} \mathrm{RF}\end{array}$ \\
ClimPolicy-CO $\mathrm{C}_{2}$ & Emission and climate effect of (1) direct $\mathrm{CH}_{4}$ mitigation, (2) indirect \\
only,ClimPolicy-CH $\mathrm{CH}_{4}$ only, & mitigation resulting from $\mathrm{CO}_{2}$ measures, (3) the combined effect of \\
ClimPolicy & both \\
\hline
\end{tabular}

\subsection{Model diagnostics and literature review}

The model diagnostics and literature review of the study is aimed at (1) understanding how differences in $\mathrm{CH}_{4}$ emission projections are influenced by underlying model assumptions, (2) how the model projections compare to estimates from literature, and how any differences can be explained. In a diagnostic exercise, the models have introduced the same high carbon price (leading up to $1250 \mathrm{USD} 2015 / \mathrm{tCO}_{2}$ in 2100). The resulting total $\mathrm{CH}_{4}$ reduction in the models can (effectively) be considered the maximum reduction potential in a multi-gas strategy (comparable to ClimPolicy). This analysis has been done as part of a much broader assessment in the ADVANCE project (Luderer et al., 2016) and is made available for this study. All models, except ENV-Linkages, have taken part in both projects. The projected sectoral emission reductions are compared to maximum emission reductions found in literature. Based on this comparison, potential opportunities and barriers for each of the emission sources are identified.

\section{Results}

\subsection{Scenario analysis}

\subsubsection{Emissions}

Figure 1 shows the projected emission levels in the five scenarios in 2050 and 2100 compared to the emissions in 2010 (Section S2 in the Supplement shows the model-specific results, including time series of the five scenarios. These also indicate that the model difference in emissions in the base year is limited to $12 \%$, in line with uncertainty found in AR5 (IPCC, 2013)). Significant cost-effective and non-climate policy related end-of-pipe reductions are already realized in the Reference case (resulting from methane recovery, safety, and air quality considerations). Virtually all these reductions occur in energy production (e.g., reduction of leakage in oil and gas production) and waste (e.g., $\mathrm{CH}_{4}$ collection from landfills) (within 2050, reductions of $26 \%$ and $13 \%$, respectively), while reductions in agriculture are very small 
$\square 2010 \square 2050 \square 2100$

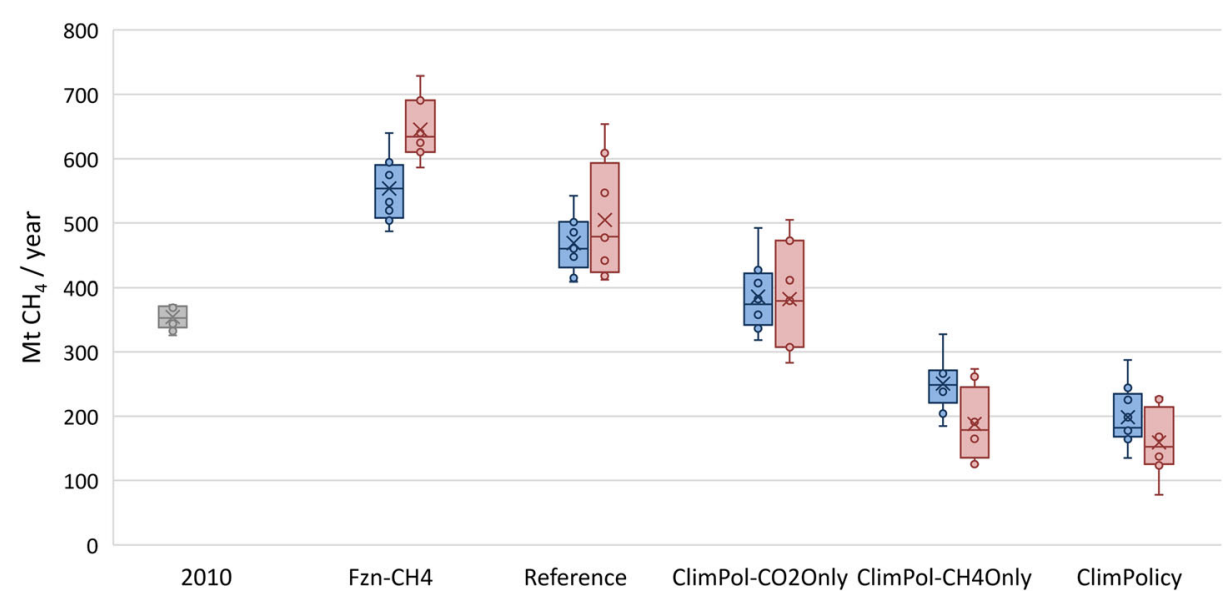

Fig. $1 \mathrm{CH}_{4}$ emissions in the five scenarios in 2050 and 2100. Emissions in 2010 are shown as a benchmark (boxplot and whiskers based on quartiles, line shows median, cross shows mean. See Section S2 in the Supplement for model-specific emissions: time series of the five scenarios, and relative emission reductions)

(Table S2.2 in the Supplement). Note that this applies to end-of-pipe measures. Structural changes, like increased feed efficiency, also reduce emissions somewhat. However, these have not been examined here, since any projected structural changes are included in both Fzn-CH4 and Reference, so do not show up as a difference in emissions between the two scenarios.

Despite the improvements in emission factors, $\mathrm{CH}_{4}$ emissions in the Reference case are projected to rise steadily by $24-47 \%$ compared to 2010 in 2050 and by $10-72 \%$ in 2100 , in line with projections used for the IPCC 5th Assessment Report (Clarke et al., 2014). Although the projection for 2100 is obviously more uncertain, the general trend is that emissions in the 2050-2100 period stabilize, driven mostly by a stabilizing global population and a decreasing importance of fossil fuels.

In the $2{ }^{\circ} \mathrm{C}$ climate policy case (ClimPolicy), the emissions are projected to be reduced, relative to Reference emissions, by 58\% (43-70\%) and 68\% (58-84\%) in 2050 and 2100, respectively, indicating that most of the reductions are realized in the short term and that smaller additional reductions are expected in the second half of the century. Emission levels in 2100 are projected to reach $159 \mathrm{Mt} \mathrm{CH}_{4} /$ year on average (range, 78-229 Mt), less than half the emissions in 2010.

All models show a larger mitigation effect resulting from measures that directly target $\mathrm{CH}_{4}$ emissions (in ClimPolicy- $\mathrm{CH}_{4}$ only) than indirectly from structural changes resulting from $\mathrm{CO}_{2}$ mitigation policy (in ClimPolicy- $\mathrm{CO}_{2}$ only); hence, the former can be considered more effective in bringing down $\mathrm{CH}_{4}$ emissions. This is in line with earlier work (Gambhir et al., 2017). In 2100 , direct mitigation alone is projected to lead to a reduction of $50 \%$ to $74 \%$ compared to the reference case, compared with $22 \%$ to $48 \%$ reduction indirectly resulting from $\mathrm{CO}_{2}$ policy.

\subsubsection{Regional breakdown}

In terms of regional emissions, Asia has the largest contribution due to its high population and large size, both with and without climate policy (see Fig. 2). Emissions from the Middle East/ Africa (MAF) region, however, show the strongest increase, which is also in line with the projected strong population growth in this region (KC and Lutz, 2017). With strong climate policy, ASIA and MAF are therefore projected to be the two regions with the largest residual 


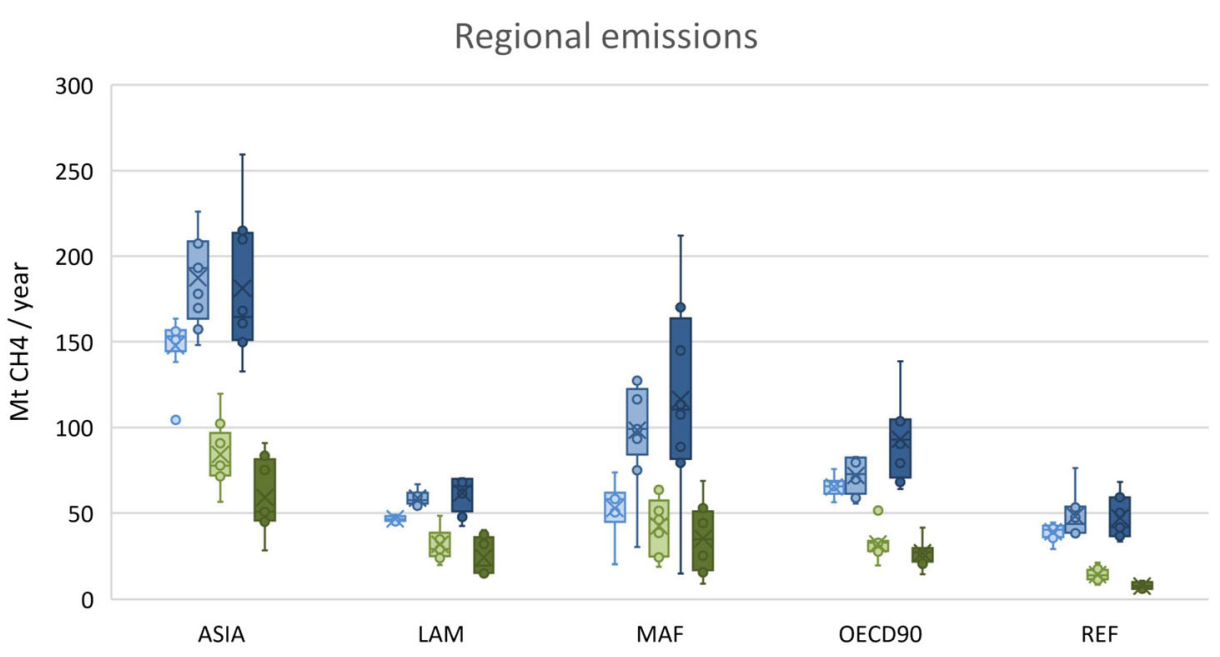

Regional emissions per capita

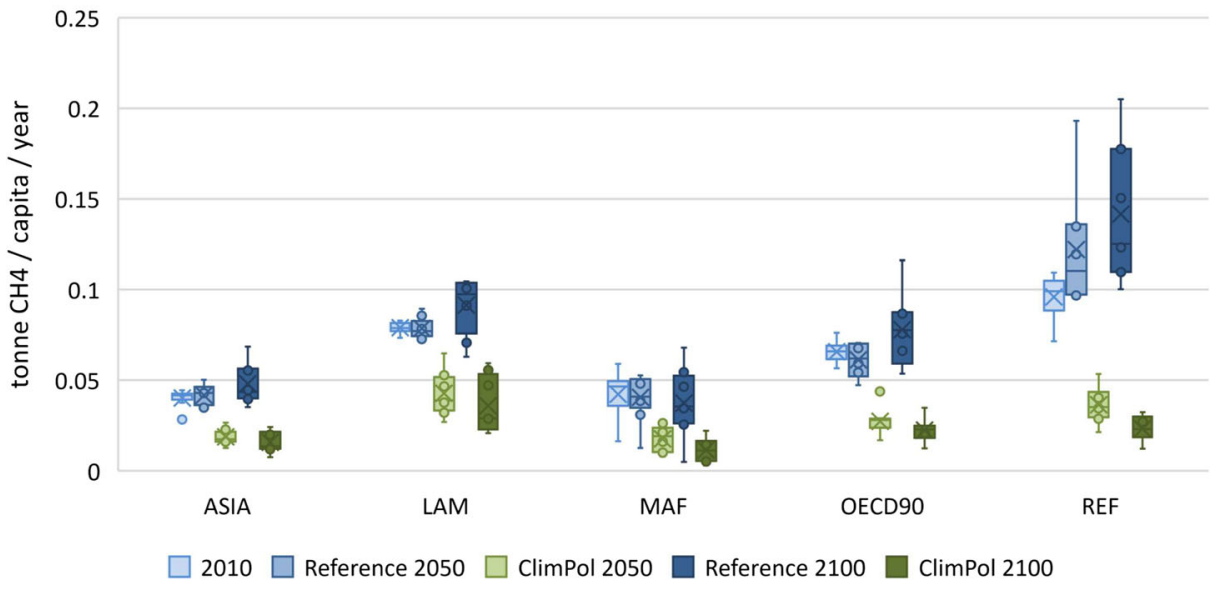

Fig. 2 Regional $\mathrm{CH}_{4}$ emissions upper panel: total emissions per region. Lower panel: per capita emissions per region (boxplot and whiskers based on quartiles, line shows median, cross shows mean. See section S3 in the Supplement for a sectoral breakdown of the per capita emissions in the world regions, and section S4 for description of the regions)

emissions, $37 \%$ and $22 \%$ of total emissions in 2100 on average. Note that the growth in MAF could also partly be increased by a global shift of fossil fuel and agricultural production to the region. However, understanding the relative influence of global demand and trade of energy and agricultural products is outside the scope of this study. In per capita terms, the picture shifts. Here, regional differences are explained by how regions differ in terms of sectoral emissions. Across the models, sectoral abatement potentials are relatively similar across regions. Regional differences, therefore, arise mainly due to structural differences, such as the role of livestock, rice cultivation, and fossil resource extraction. In the Reference case, models consistently show that the highest per capita emissions are found in REF (Reforming economies of E. Europe/ former Soviet Union; mostly because of $\mathrm{CH}_{4}$ emissions from gas extraction) followed by LAM 
(Latin America; mostly livestock sector), while ASIA and MAF emissions are the lowest (see section S3 in the Supplement for a sectoral breakdown of the per capita emissions in the world regions). With strong climate policy, residual per capita emissions originate predominantly from agriculture and are projected to be the highest in LAM, due to the relatively large share of livestock emissions. This source is characterized by high emission factors and low abatement potentials (note that although rice $\mathrm{CH}_{4}$ emissions constitute about a third of $\mathrm{CH}_{4}$ emissions in Asia, in per capita terms, this is much less emission-intensive than livestock).

\subsubsection{Global sectoral breakdown}

Fig. 3 shows the projected development of sectoral $\mathrm{CH}_{4}$ emissions in the Reference and ClimPolicy cases. In 2010, agriculture emissions (from livestock, rice, and other crops) are found to be the largest anthropogenic source (43-49\% of total emissions), followed by energy supply and demand (32-39\%), and waste (16-22\%). Without climate policy, emissions from all three main aggregated sectors will continue to increase, with similar growth rates (i.e., their relative contribution to total emissions are not expected to change much in time, see Supplement S3). In ClimPolicy scenario, energy emissions are expected to decrease dramatically, due to a combination of direct mitigation and a reduction of fossil fuel. Waste emissions in 2100 are expected to decrease by half compared to 2010, while agriculture emissions are projected to only slightly decrease or even remain stable. This difference in sectoral mitigation potential makes agriculture $\mathrm{CH}_{4}$ emissions by far the largest source of remaining emissions under the climate policy scenario: $60-80 \%$ in of total emissions 2050 and $55-88 \%$ in 2100.

In Fig. 4, the relatively large reductions in the energy sector are visualized by comparing Reference and the three mitigation scenarios in a primary energy use vs. emission factor plot for 2050 (see also Figure S3.5 in the Supplement for the projections for 2100, when the situation is comparable, but with deeper reductions). The figure shows that even in the energy supply sectors, both reduced fossil fuel use and end-of-pipe measures contribute significantly

$\square$ Energy Supply and Demand $\square$ Agriculture $\square$ Waste

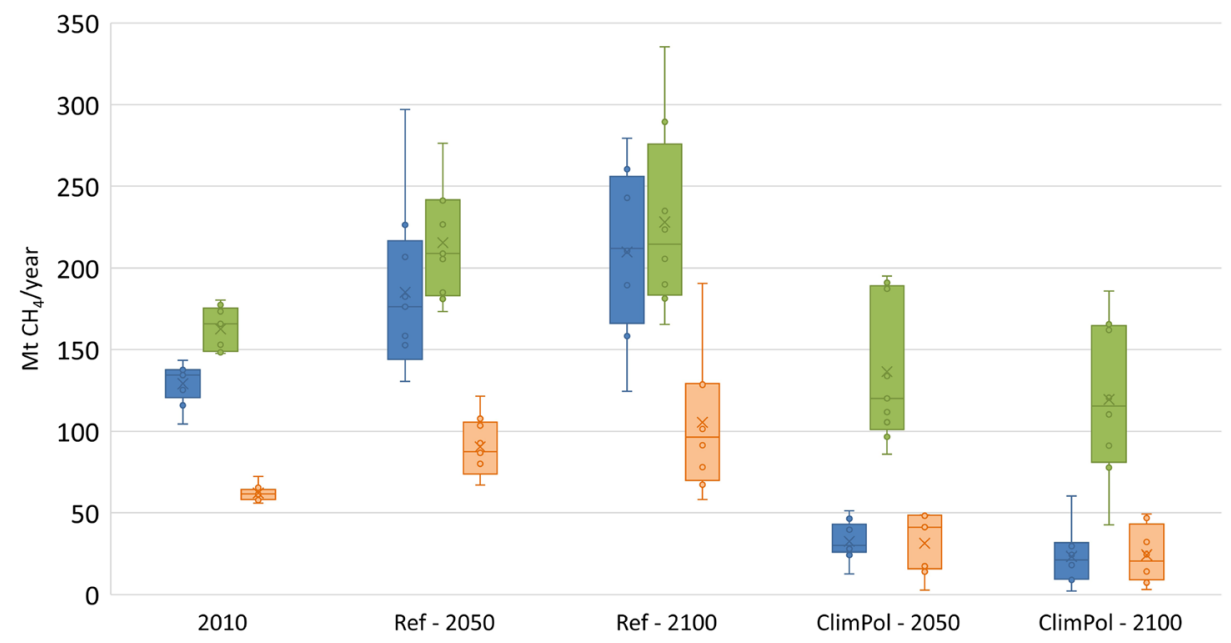

Fig. 3 Global $\mathrm{CH}_{4}$ emissions in the no policy Reference and $2{ }^{\circ} \mathrm{C}$ ClimPolicy cases for 2050 and 2100. Subdivision into (1) energy supply and demand (2) agriculture and (3) waste (boxplot and whiskers based on quartiles, line shows median, cross shows mean. See in Supplement S3: (a) model-specific results (Fig. S3) and (b) sectoral emissions relative to global total (Fig. S4).Electronic supplementary material 


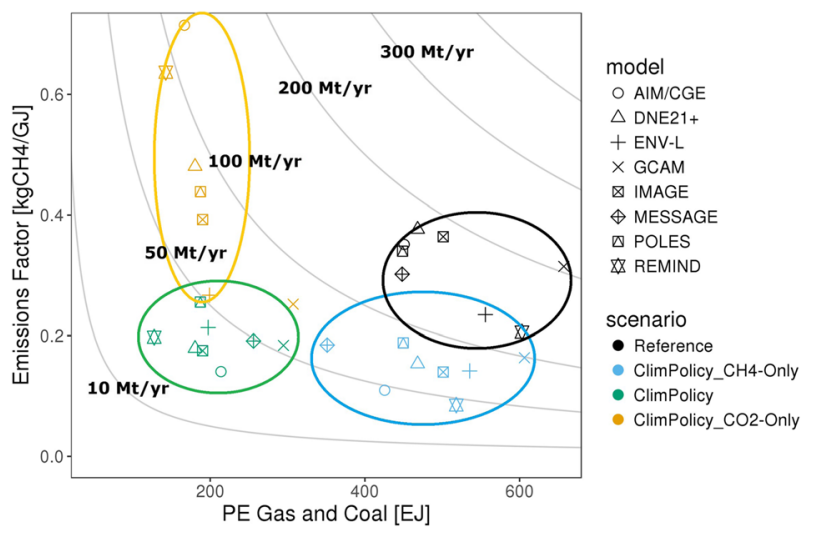

Fig. 4 Primary energy (PE) (coal and natural gas) vs. $\mathrm{CH}_{4}$ emission factor from global energy supply in 2050. Hyperbolic iso-lines represent locations in the graph with equal yearly emissions (values indicated in bold). Projections quantitatively lie between two neighboring iso-lines (see Fig. S3.5 in the Supplement for 2100 plot)

to reducing emissions. End-of-pipe measures alone (in ClimPolicy-CH4Only) or $\mathrm{CO}_{2}$ measures alone (reducing fossil fuel production, in ClimPolicy-CO2Only) would both bring global energy supply $\mathrm{CH}_{4}$ emissions from the 100-200 Mt/year range (in Reference) to the 50$100 \mathrm{Mt} /$ year range. Residual emissions in ClimPolicy-CO2Only occur due to a lack of incentives for end-of-pipe measures to abate $\mathrm{CH} 4$ emissions from remaining fossil fuel use, while in ClimPolicy-CH4Only, the absence of $\mathrm{CO}_{2}$ pricing disincentivises a switch away from coal and gas towards non-fossil energy carriers. Only the combination of $\mathrm{CH}_{4}$ and $\mathrm{CO}_{2}$ pricing (in ClimPolicy) achieves deeper $\mathrm{CH}_{4}$ emission reductions towards about 25-50 Mt/year.

\subsection{Diagnostic analysis and literature comparison}

In the diagnostic exercise, the models have been driven by the same carbon price level, applied to all GHGs, to compare the elasticity of $\mathrm{CH}_{4}$ emissions to a greenhouse gas tax (note that all models participated, except ENV-Linkages, which was not part of the ADVANCE project where the analysis was performed and DNE21+, which included scenarios up until 2050). Figure 5 shows the models' $\mathrm{CH}_{4}$ emission reduction under an increasing carbon price compared to a situation with no carbon price (Reference). The reductions shown are the combined effect of both end-of-pipe measures and indirect reductions due to $\mathrm{CO}_{2}$ mitigation, comparable to the case in ClimPolicy. The maximum carbon price in 2100 of $1500 \$(2005) / \mathrm{tCO}_{2}$ is higher than any of the models' projected carbon price in ClimPolicy and near the high end of the range of projected maximum carbon prices in other multimodel studies such as the SSPs (Riahi et al., 2017). Therefore, the projected reductions for 2100 can effectively be considered the maximum reduction potentials (MRPs).

There is a relatively good agreement in projected $\mathrm{CH}_{4}$ emission reductions relative to baseline (between $64 \%$ and $82 \%$, with most models between $64 \%$ and $72 \%$ ) despite large differences in sectoral reduction potentials (see next section). The highest reduction is seen in POLES, leading up to $82 \%$ in 2100 . Mainly, this is the result of very optimistic assumptions on reductions in agriculture (up to $74 \%$ ). ${ }^{3}$ AIM/CGE also stands out with a relatively high MRP

\footnotetext{
${ }^{3}$ Figure refers to world aggregate. Reductions in agriculture result from country-specific marginal abatement cost curves derived from multiple runs of the GLOBIOM model, with a linear extrapolation for high carbon prices. In more recent model configurations, without extrapolation, the resulting world MRP is $63 \%$ in 2100 .
} 


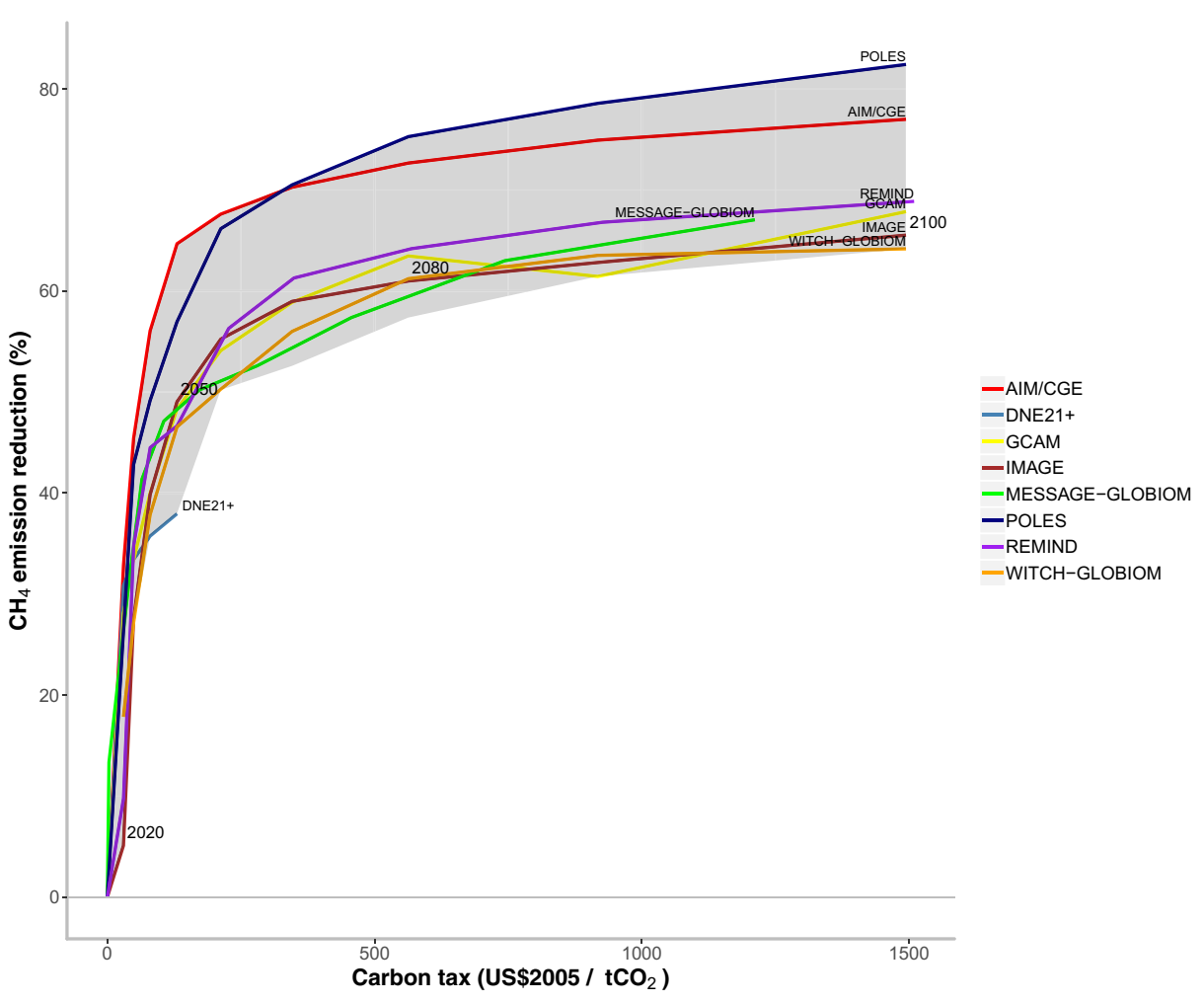

Fig. 5 Diagnostic analysis: $\mathrm{CH}_{4}$ reduction sensitivity to high carbon price (up to 1500 USD2005 or 1250 USD2015 in 2100. Development carbon price: no carbon price before the year 2020. After 2020, price (year) = $80(2005) \$ \times 1.05^{\wedge}$ (year-2040). Gray-shaded area shows a full model range of participating models in the ADVANCE project (ENV-Linkages did not take part)

(up to $79 \%$ in 2100), mainly resulting from extrapolation of the underlying MAC data (Lucas et al., 2007), leading to relatively high sectoral reduction potentials.

Consistently across models, there is an increasing MRP as carbon prices increase to very high values. This is driven by three effects that vary in influence in the models: (1) increased potential in the MAC curves at high prices, (2) indirect mitigation from $\mathrm{CO}_{2}$ policy, and (3) economic feedbacks from high methane prices (i.e., lower demand for methane-intensive products). Regarding the first effect (1), POLES, AIM/CGE, DNE21+, ENV-Linkages, and MESSAGEGLOBIOM make use of marginal abatement cost (MAC) curves that are (sometimes partly) based on extrapolation of underlying datasets, which allows for slowly increasing reduction levels under increasingly high carbon prices. The other models have assumed sectoral MRPs or marginal abatement cost curves that do not allow further reductions at a specific price (see Supplement S5 for model-specific MAC data and additional assumptions/modifications). The indirect mitigation effect from $\mathrm{CO}_{2}$ mitigation (2) is strongest in GCAM and IMAGE, followed by WITCH2016, DNE21+, and AIM (see Supplement S2). Economic feedbacks from methane prices on the demand of heavily methane-producing activities (3) (e.g., fossil fuel and livestock production) have been modeled in AIM/CGE, ENV-Linkages, GCAM, MESSAGE, and REMIND.

Figure 6 gives an overview of the models' source-specific MRPs (and in the case of POLES, $\mathrm{AIM}$, and MESSAGE, the reduction potential at $\left.1500 \$ / \mathrm{tCO}_{2}\right)$ compared to reduction potentials found in recent bottom-up studies of $\mathrm{CH}_{4}$ MAC curves (Harmsen et al. 2019; Höglund- 


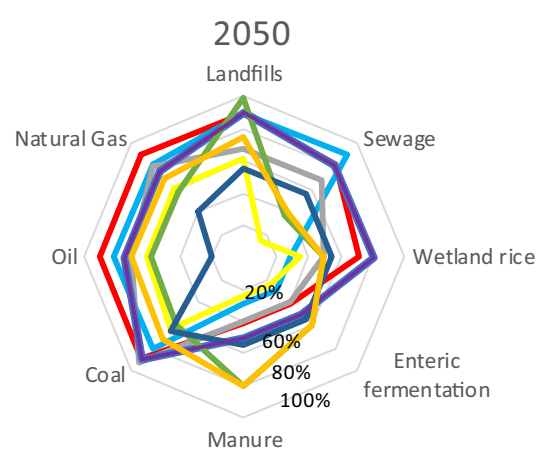

2100

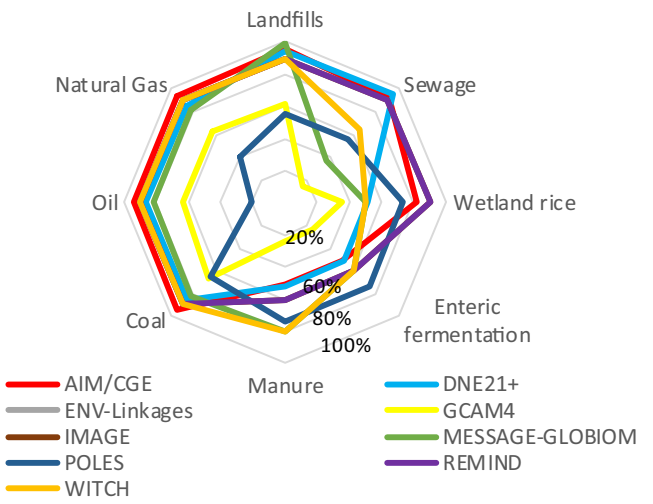

2050

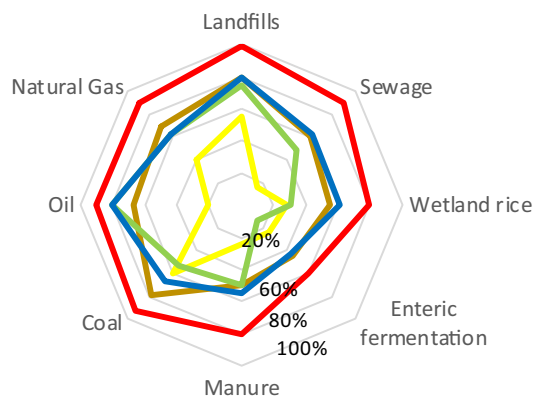

2100

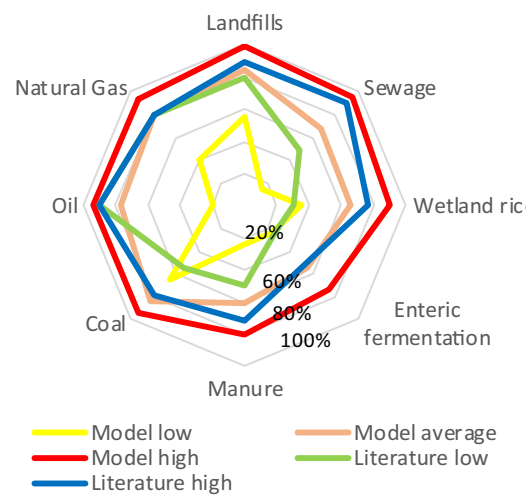

Fig. 6 Maximum reduction potentials per emission source in 2050 and 2100 as assumed by the models (in \%, see numbering right below in each diagram) (in case a model's MRPs are region dependent, the figure shows the global average) Left panels: source-specific MRPs in 2050 and 2100 (note, IMAGE and REMIND overlap, because of the use of the same MACs) Right panels: minimum, average, and maximum MRP compared to longterm source-specific reduction potentials found in recent literature (Harmsen et al., 2018; Höglund-Isaksson, 2012, 2017; 2015) (see in Supplement S5: (1) data sources per model (Table S5.1) and (2) reduction potentials per source (Table S5.2 and Fig. S5.1). See in Supplement S6: description of background literature in Harmsen et al., 2018)

Isaksson, 2012, 2017; 2015) (see Supplement S6 for results from Harmsen et al. 2019). It can be seen that MRP assumptions differ substantially across models, especially in 2050. Even when using the same data source, differences can be substantial (see fig. S5.1 in the Supplement), indicating that models add additional assumptions to MAC curve data. In 2100, the MRPs for the fossil fuel sectors and for landfills/solid waste are generally higher than $90 \%$ (except in POLES and GCAM, based on GECS 2002 and US-EPA 2013). There is large uncertainty about the MRP of wastewater and of the three main agriculture sources: enteric fermentation, rice, and manure. For the agricultural sources, the MRPs are generally also much lower in all models (between $25 \%$ and $60 \%$ in 2100 ).

The maximum MRP values (i.e., the highest found among the models) are higher (so more ambitious) than any of the reduction potentials found in recent literature, and for several sources, the average MRPs can be considered on the high end of what is found in literature (see right panel). The higher MRPs in the models can partly be explained by the optimistic estimates (for coal, natural gas, and wetland rice) from Lucas et al. (2007) (used by AIM/CGE, IMAGE, and REMIND) as well as extrapolations of reduction potentials at higher carbon 


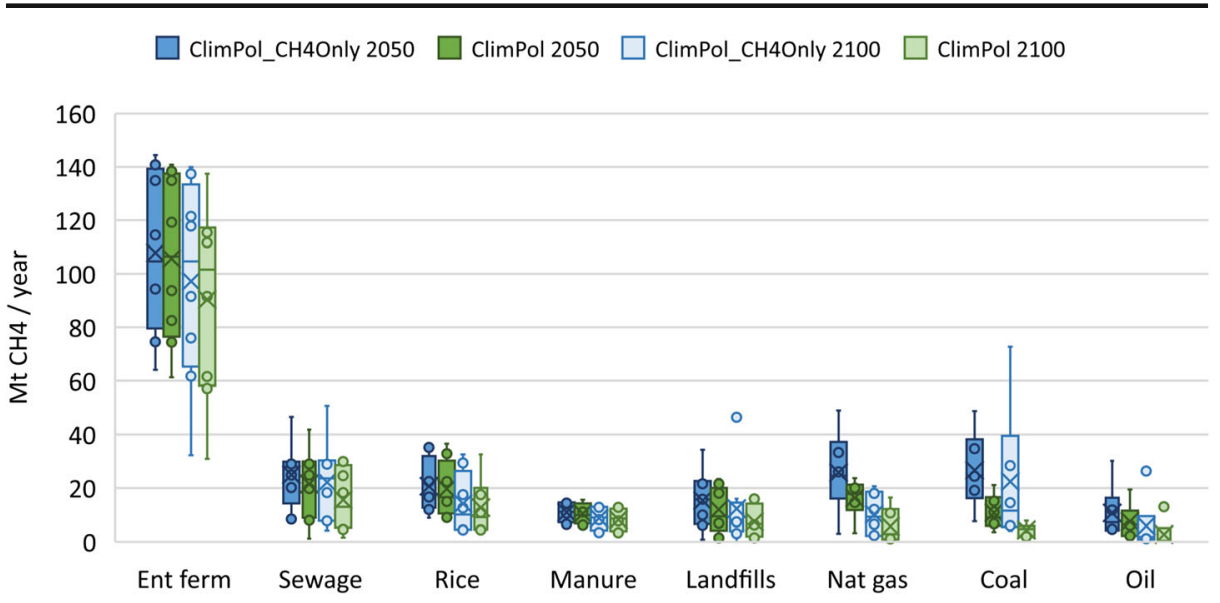

Fig. 7 Source-specific $\mathrm{CH}_{4}$ emissions in ClimPolicy- $\mathrm{CH}_{4}$ only and ClimPolicy, for 2050 and 2100 in order of high to low emissions in 2100 in ClimPolicy (boxplot and whiskers based on quartiles, line shows median, cross shows mean. Whenever models only represent emissions on an aggregated sector level, the breakdown of emissions by source has been based on the average ratio from the other models. Energy demand/combustion, savanna burning, deforestation, and agricultural waste burning are not shown, because these emissions are projected to be very low: $5 \%$ of the global emissions in total and no explicit mitigation measures have been modeled for these sources). See Fig. S5.2 in the Supplement for relative reductions per sector, including a comparison with the models' MRPs

prices (e.g., for enteric fermentation). Note, however, that models do not always reach their MRP due to too low carbon prices or inertia in the speed of emission reduction (e.g., in IMAGE and POLES). In addition, Höglund-Isaksson et al., (2012, 2015) used as a comparison here is based on the technical potential of currently known technologies and can be considered relatively conservative. However, when considering the maximum MRPs, it can be concluded that some models assume that technology improvements and global implementations go beyond what is found in recent literature.

Figure 7 shows yearly emissions per source in 2050 and 2100 in ClimPolicy- $\mathrm{CH}_{4}$ only and ClimPolicy (see also Fig. S5.2 in the Supplement for the relative reductions by source, including a comparison with the models MRPs). The projected emission ranges are large, indicating large uncertainties for all sources. There are no drastic changes between 2050 and 2100. However, the models' MRPs are generally not fully reached in 2050, while in 2100, this is usually almost the case (then ClimPolicy- $\mathrm{CH}_{4}$ only is almost MRP, with less than $5 \%$ difference in $95 \%$ of the cases). In ClimPolicy, reduction is clearly higher than in ClimPolicy$\mathrm{CH}_{4}$ only, particularly in the coal/oil/natural gas sectors, due to a reduction in the use of fossil fuels. With strong mitigation in 2100, the fossil fuel sectors are responsible for 5-28 Mt/year, or $3.5-18 \%$ of total $\mathrm{CH}_{4}$.

All models agree that enteric fermentation in ruminants can by far be considered the largest remaining mitigation bottleneck in a strong climate policy case. In ClimPolicy in 2100, emissions are projected to be an average $90 \mathrm{Mt} /$ year (range, 31-137 Mt) or 58\% (40-87\%) of total emissions. These reductions are to a large extent realized by end-of-pipe measures and not by any human dietary changes, since this is not incorporated in the models' MAC curves (note that most models do include price feedbacks, where ruminant meat and dairy demand is lowered somewhat as a result of higher $\mathrm{CH}_{4}$ prices). The average reduction in $2100(55 \%)$ is comparable with the MRP estimated in Harmsen et al. (2019): 52\%. This could be realized if all existing technologies (e.g., breeding through genetic selection, food supplements) would 
further develop and be optimally introduced worldwide. Höglund-Isaksson (2012) estimates the technical reduction potential at $50 \%$, but only if there would be a large diet shift away from ruminant meat consumption. Due to physiological limitations, it seems very unlikely that much higher reductions $(>60 \%)$ are feasible without a global change in diets and/or a largescale introduction of cultivated meat products.

For the remaining emission sources, the average model projections are generally in line with existing literature, although options for improvements exist and ranges in model outcomes are large, indicating substantial uncertainty (see Table S5.2 in the Supplement). Sewage and wastewater emissions are projected to be the second largest remaining emission source (with very large uncertainty). If all countries would reach the same per capita emissions as in OECD Europe, emission reductions would be $90 \%$ (Harmsen et al., 2019; US-EPA, 2013). This would require a large-scale implementation of centralized aerobic wastewater treatment systems, improvement of the $\mathrm{CH}_{4}$ recovery rate of existing plants, and additional abatement options for anaerobic treatment. With a reduction of $8 \%$ to $94 \%$ in ClimPolicy 2100 (average: 52\%), some of the model projections can be considered conservative.

Projected emission reductions for rice also differ considerably across the models (in ClimPolicy, $29-87 \%$ in 2100) as do estimates from literature: In $2100,31 \%$ according to Höglund-Isaksson (2012) and 77\% according to Harmsen et al. (2019). The latter study assumes implementation of extra measures (see Supplement S6), maximized implementation potential, and technological improvements. Even in such a case, residual global emissions around $10 \mathrm{Mt}$ /year may be unavoidable.

The models project an emission reduction of $20-74 \%$ of $\mathrm{CH}_{4}$ emissions from manure in ClimPolicy in 2100. Anaerobic digesters, centralized or farm scale, combined with efficient and enclosed manure collection and processing could bring down emissions by $75 \%$ or more if further developed (Graus et al., 2004). However, it is unlikely that this will ever be viable and implemented in the least developed regions, in particular for non-confined ruminant livestock. With very high carbon prices enforced worldwide, and maximized free trade, emission reductions could still be considerable, by reallocation of livestock production towards more efficient and less GHG intensive systems (Havlík et al., 2014).

For landfills and solid waste $\mathrm{CH}_{4}$ mitigation, a whole range of options exist that can bring down emissions, varying from waste diversion (recycling and reuse), to $\mathrm{CH}_{4}$ utilization and flaring, and all studies agree that high MRPs (80-90\%) are feasible. The models project reductions of 37-99\% (average 79\%) in ClimPolicy in 2100, resulting in $7.5 \mathrm{Mt} \mathrm{CH}_{4} /$ year residual emissions on average.

\subsection{Climate impacts}

Figure 8 gives an overview of $\mathrm{CH}_{4}$ radiative forcing (RF) and total global mean temperature (GMT) effects in the five scenarios for 2050 and 2100 (present-day values are provided in the caption). The upper left panel shows that when unabated (in Reference), direct $\mathrm{CH}_{4} \mathrm{RF}$ increases from $0.59 \mathrm{~W} / \mathrm{m}^{2}$ today to $0.81 \mathrm{~W} / \mathrm{m}^{2}$ (range, $0.69-1.0 \mathrm{~W} / \mathrm{m}^{2}$ ) in 2100 , whereas with strong climate policy (in ClimPolicy), present-day RF can almost be halved to $0.34 \mathrm{~W} / \mathrm{m}^{2}$ (range, $0.26-0.44 \mathrm{~W} / \mathrm{m}^{2}$ ). The total forcing difference between Reference and ClimPolicy resulting from the difference in $\mathrm{CH}_{4}$ emissions is in fact even larger, as $\mathrm{CH}_{4}$ contributes to tropospheric ozone $\left(\mathrm{O}_{3}\right)$ forcing (as an $\mathrm{O}_{3}$ precursor), stratospheric $\mathrm{H}_{2} \mathrm{O}$ forcing, and $\mathrm{HFC}$ forcing (by affecting HFC atmospheric lifetimes). 

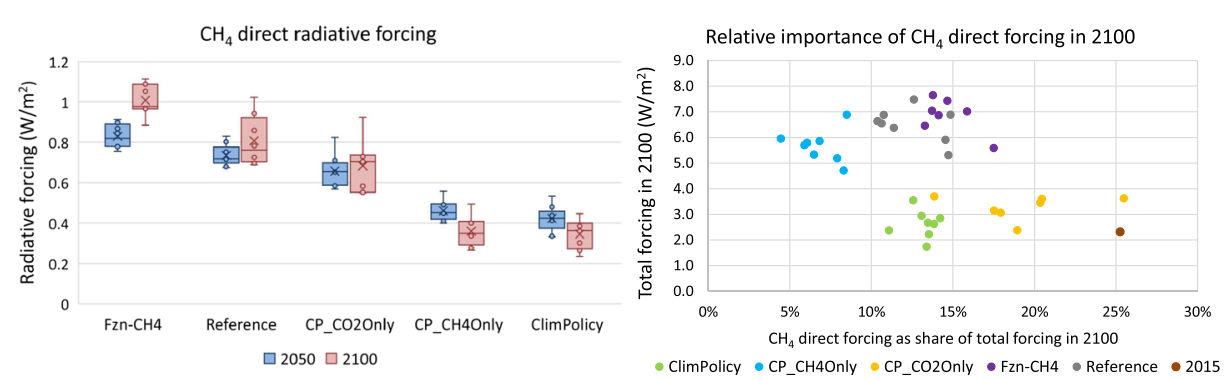

Temperature Change

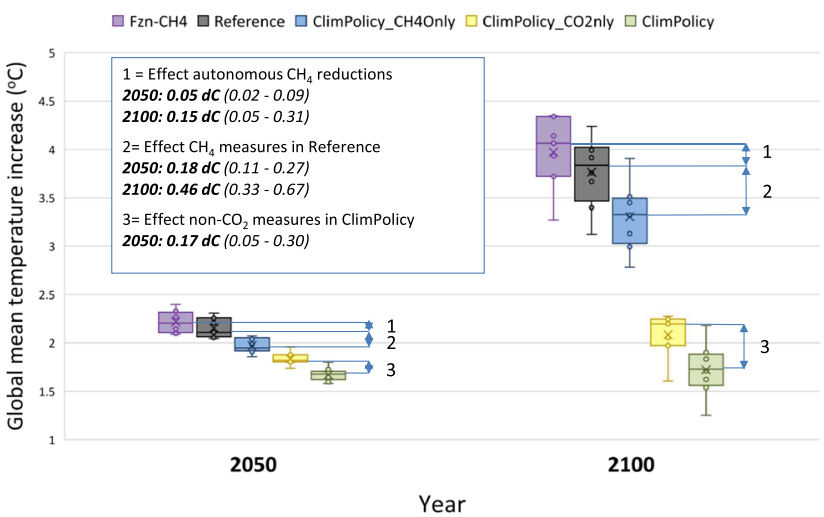

Fig. 8 Climate impacts upper left panel $\mathrm{CH}_{4}$ direct radiative forcing (RF) in 2050 and $2100\left(\mathrm{CH}_{4}\right.$ direct $\mathrm{RF}$ in 2015 is: $0.59 \mathrm{~W} / \mathrm{m}^{2}$ ). Upper right panel: $\mathrm{CH}_{4}$ direct $\mathrm{RF}$ as share of total forcing in 2100 for the five scenarios (the value in 2015 is shown as a benchmark). Lower panel: temperature change in the five scenarios in 2050 and 2100 (temperature change in 2015 is $1.09^{\circ} \mathrm{C}$ ) (boxplot and whiskers based on quartiles, line shows median, cross shows mean)

The upper left panel also shows that the direct $\mathrm{CH}_{4}$ forcing in ClimPolicy_ $\mathrm{CH}_{4}$ only is very close to the direct forcing in ClimPolicy (much closer than the $\mathrm{CH}_{4}$ emissions in the two scenarios; see Fig. 1). This is the result of a shorter $\mathrm{CH}_{4}$ lifetime in ClimPolicy_CH $\mathrm{CH}_{4}$ only, since the lifetime of $\mathrm{CH}_{4}$ is indirectly dependent on $\mathrm{NO}_{\mathrm{x}}, \mathrm{CO}$, and $\mathrm{VOC}$ concentrations, through its relation with tropospheric $\mathrm{OH}$ (Meinshausen et al., 2011).

Note in the upper right panel that in both Reference and ClimPolicy, the relative contribution of direct $\mathrm{CH}_{4}$ to total forcing decreases in time, as it is short-lived and does not accumulate in the atmosphere as much as $\mathrm{CO}_{2}$ and $\mathrm{N}_{2} \mathrm{O}$ (see Supplement $\mathrm{S} 7$ for forcer specific RF). Despite this decrease, $\mathrm{CH}_{4}$ is still projected as the most influential GHG second to $\mathrm{CO}_{2}$. This is clearly the case if no direct $\mathrm{CH}_{4}$ regulation would be enforced (in ClimPolicy- $\mathrm{CO}_{2}$ only in 2100 , direct $\mathrm{CH}_{4}$ forcing constitutes $19 \%$ of total forcing on average), but also with maximum mitigation in a 2-degree scenario (on average, $13 \%$ of total forcing comes from $\mathrm{CH}_{4}$ in ClimPolicy in 2100), especially when considering the additional indirect contribution of $\mathrm{CH}_{4}$ to total forcing.

The lower panel shows the temperature differences between the five scenarios in 2050 and 2100 , thus indicating the relevance of $\mathrm{CH}_{4}$ reducing measures. In 2100 , cost-effective and nonclimate policy-related $\mathrm{CH}_{4}$ reductions in the Reference case would reduce GMT $0.15{ }^{\circ} \mathrm{C}$ on average compared to Fzn-CH4, while strong $\mathrm{CH}_{4}$ mitigation policy (in ClimPolicy_CH $\mathrm{CH}_{4}$ only) can further bring down GMT by $0.46{ }^{\circ} \mathrm{C}$ (or $12 \%$ of total GMT change), in line with a similar assessment by Rogelj et al. (2015). The temperature difference between ClimPolicy- $\mathrm{CO}_{2}$ only 
and ClimPolicy represents the effect of including non- $\mathrm{CO}_{2}$ emissions in a $2{ }^{\circ} \mathrm{C}$ climate strategy, which amounts to $0.33{ }^{\circ} \mathrm{C}$ (or $16.5 \%$ of total GMT change) in 2100 on average. Although the exact value cannot be determined based on this assessment, more than half this difference can likely be attributed to $\mathrm{CH}_{4}$ mitigation (consistent with the estimate by Rogelj et al. $\left.2015 ; 0.25{ }^{\circ} \mathrm{C}\right)$. Roughly half of the forcing difference between the two scenarios $(47 \%$ on average in 2100) results from differences in direct $\mathrm{CH}_{4}$ forcing, and the total temperature increase from $\mathrm{CH}_{4}$ is estimated at $140 \%$ of the temperature increase from direct forcing alone (Smith et al., 2012). Note also that, particularly in the long term, some models have substantial indirect $\mathrm{CO}_{2}$ forcing reductions in ClimPolicy_ $\mathrm{CH}_{4}$ only, due to increased fossil fuel prices resulting in $\mathrm{CO}_{2}$ concentration decreases (see discussion elsewhere in this special issue (Smith, 2018)).

Note that the results might be influenced by recent studies that could change the understanding of the climatic role of $\mathrm{CH}_{4}$. According to Etminan et al. (2016), the present-day RF of $\mathrm{CH}_{4}$ has been historically underestimated and should be increased by $25 \%$. Additionally, Modak et al. (2018) suggest that efficacy (effective impact of RF on GMT) for $\mathrm{CH}_{4}$ should be reduced (17\% lower than earlier assumed). In terms of impact on GMT, these factors may partially compensate each other.

\section{Discussion and conclusions}

\subsection{Discussion}

Although this study has a comprehensive coverage of anthropogenic $\mathrm{CH}_{4}$ sources, there are several factors that could influence the conclusions.

The possible range in structural economic shifts (changes in diet patterns, relocation of agricultural production, increased waste incineration) is only partly included in the scenarios, in the sense that these are based on the moderate socioeconomic developments of SSP2 combined with a $2{ }^{\circ} \mathrm{C}$ target. However, note that in the complete set of stringent mitigation scenarios in the SSPs (including those more green-growth oriented (SSP1) or unsustainable (SSP3) socioeconomic assumptions, and $1.5^{\circ} \mathrm{C}$ targets), there are only a few exceptions that fall outside the global $\mathrm{CH}_{4}$ emission projections in this study (GCAM, with up to $92 \mathrm{Mt} \mathrm{CH}_{4}$ higher emissions in the $2{ }^{\circ} \mathrm{C}$ case and AIM/CGE, with up to $31 \mathrm{Mt} \mathrm{CH}_{4}$ lower emissions in the $1.5^{\circ} \mathrm{C}$ case) (Riahi et al., 2017).

While $\mathrm{CH}_{4}$ from wetlands is a natural source and therefore not included in this study, human-induced reduction and management of wetlands can have a large effect on emissions, positively or negatively, as total wetland emissions are very high (155-235 $\mathrm{Mt} \mathrm{CH}_{4} /$ year (Saunois et al., 2016)). This anthropogenic effect is highly uncertain and therefore poorly represented in most models.

The incorporated $\mathrm{CH}_{4}$ MAC curves are to a large extent based on existing or envisioned technologies. Although the models take unforeseen technological improvements into account by assuming deeper reductions at higher costs and in the longer term, than what is found in literature, this is also highly uncertain and represented quite differently across the models (indicated by a large spread in sectoral reduction potentials). The models could improve by updating the underlying MAC data, which, in many cases, is more than 10 years old. However, note that, to a large extent, the uncertain association with technological change also applies to the estimates derived from literature. Harmsen et al. (2019) provide single value estimates of reduction potentials per sector, which rely on a range of uncertain assumptions (See Supplement S6), which, if varied, would also lead to an uncertainty of range in sectoral reduction potentials. 
By including multiple models in our study, much of this intrinsic uncertainty is captured, giving more confidence in the robust results across models (i.e., this study's main conclusions).

\subsection{Conclusions}

$\mathrm{CH}_{4}$ emissions from all three main aggregated sectors, fossil energy supply, agriculture, and waste, are projected to continue to increase steadily without climate policy, up to $150 \%$ of current (2010) emissions in 2100. Significant cost-effective and non-climate policy-related reductions (7-28\% less in 2050 and 10-36\% less in 2100, largely due to the use of fugitive $\mathrm{CH}_{4}$ emissions as an energy source) are expected to reduce emissions somewhat, but will not affect the general trend. While there are strong co-benefits with $\mathrm{CO}_{2}$ mitigation, direct $\mathrm{CH}_{4}$ mitigation is crucial and most effective in bringing down total $\mathrm{CH}_{4}$ emissions.

In a stringent $\left(2{ }^{\circ} \mathrm{C}\right)$ climate policy scenario, energy $\mathrm{CH}_{4}$ emissions are expected to decrease dramatically due to a combination of direct $\mathrm{CH}_{4}$ abatement and a concurrent reduction in fossil fuel use. Waste emissions are decreased by half, while agriculture emissions are projected to only slightly decrease or even remain stable. Asia has the largest contribution to total $\mathrm{CH}_{4}$ emissions, although in relative terms that contribution declines in time. Per capita emissions in Latin America are projected to be the highest in 2100 , due to a relatively high concentration of livestock.

Enteric fermentation in ruminants is by far the largest bottleneck by the end of the century. In a $2{ }^{\circ} \mathrm{C}$ case in 2100 , emissions are estimated at $87 \mathrm{Mt} /$ year (range, 31-137 Mt) or 57\% (20$91 \%$ ) of total emissions. It seems unlikely that these residual emissions can be avoided without a global change in human diets towards monogastric meat or an increasingly plant-based diet.

In terms of the maximum global $\mathrm{CH}_{4}$ reduction, there is a relatively large consensus (with most models projecting a maximum reduction between $64 \%$ and $72 \%$ compared to no climate policy), despite much larger differences in sector and source-specific reduction. In 2100, the maximum reduction potentials (MRPs) for the fossil fuel sectors and for landfills/solid waste are generally higher than $90 \%$. There is large uncertainty about the MRP of wastewater and of the three main agriculture sources: enteric fermentation, rice, and manure, which are generally also much lower in all models (between $25 \%$ and $60 \%$ in 2100). The models' MRPs can be considered on the high end of what is found in literature.

In all scenarios, the relative contribution of direct $\mathrm{CH}_{4}$ forcing to total forcing will decline; however, $\mathrm{CH}_{4}$ will remain the second most important GHG after $\mathrm{CO}_{2}$, with $13 \%$ (11-14\%) of total radiative forcing in the $2{ }^{\circ} \mathrm{C}$ case. This is also reflected in the temperature reducing potential of $\mathrm{CH}_{4}$ mitigation measures (around $10 \%$ of the total temperature change in 2100); thus, optimizing mitigation is crucial in reaching low climate targets.

Acknowledgments The research leading to these results has received funding from CWF (IIA/17/1303). We would like to thank them and our colleagues who have directly or indirectly supported the work within the EMF30 consortium. We would like to thank them and our colleagues who have directly or indirectly supported the work within the EMF30 consortium.

Funding information The research leading to these results has received funding from CWF (IIA/17/1303).

Open Access This article is distributed under the terms of the Creative Commons Attribution 4.0 International License (http://creativecommons.org/licenses/by/4.0/), which permits unrestricted use, distribution, and reproduction in any medium, provided you give appropriate credit to the original author(s) and the source, provide a link to the Creative Commons license, and indicate if changes were made. 


\section{References}

Clarke L, et al. (2014) Assessing transformation pathways. In: Climate Change 2014: Mitigation of Climate Change. Contribution of Working Group III to the Fifth Assessment Report of the Intergovernmental Panel on Climate Change

EMF (2019) Energy Modeling Forum (EMF)-30 Study on Short-Lived Climate Forcers (SLCF) and Air Quality. https:/emf.stanford.edu/projects/emf-30-short-lived-climate-forcers-air-quality

Etminan $\mathrm{M}$ et al (2016) Radiative forcing of carbon dioxide, methane, and nitrous oxide: a significant revision of the methane radiative forcing. Geophys Res Lett 43

Gambhir A et al (2017) The contribution of non-CO2 greenhouse gas mitigation to achieving long-term temperature goals. Energies 10:602

GECS (2002) Greenhouse gas emission control strategies - research project N EVK2-CT-1999-00010. Thematic Programme : Environment and Sustainable Development of the DG Research Fifth Framework Programme

Gernaat DEHJ et al (2015) Understanding the contribution of non-carbon dioxide gases in deep mitigation scenarios. Glob Environ Chang 33:142-153

Graus WJ, et al. (2004) Marginal GHG-Abatement curves for agriculture. Ecofys report, EEP030339, April 2004

Harmsen $\mathrm{M}$ et al. (2019) Long-term emission reduction potential of non-CO2 greenhouse gases. Environmental Science \& Policy (in press)

Harmsen $\mathrm{M}$ et al (2015) How well do integrated assessment models represent non-CO2 radiative forcing? Clim Chang 133:565-582

Havlík P et al (2014) Climate change mitigation through livestock system transitions. PNAS 111:3709-3714

Höglund-Isaksson L (2012) Global anthropogenic methane emissions 2005-2030: technical mitigation potentials and costs. Atmos Chem Phys 12:9079-9096

Höglund-Isaksson L (2017) Bottom-up simulations of methane and ethane emissions from global oil and gas systems 1980 to 2012. Environ Res Lett 12

Höglund-Isaksson L et al (2015) AMAP chapter 5 CH4: AMAP assessment 2015: methane as an Arctic climate forcer: chapter 5: anthropogenic methane sources, emissions and future projections. Arctic Monitoring and Assessment Programme 2015:JRC99758

IPCC (2013) Annex II: climate system scenario tables. In: Prather M, Flato G, Friedlingstein P, Jones C, Lamarque J-F, Liao H, Rasch P (eds) Climate change 2013: The Physical Science Basis. Contribution of Working Group I to the Fifth Assessment Report of the Intergovernmental Panel on Climate Change. Cambridge University Press, Cambridge

KC S, Lutz W (2017) The human core of the shared socioeconomic pathways: population scenarios by age, sex and level of education for all countries to 2100. Glob Environ Chang 42:181-192

Kriegler E et al (2014) Making or breaking climate targets: the AMPERE study on staged accession scenarios for climate policy. Technol Forecast Soc Chang

Lucas PL et al (2007) Long-term reduction potential of non- $\mathrm{CO}_{2}$ greenhouse gases. Environ Sci Pol 10:85-103

Luderer G, et al. (2016) Deep decarbonisation towards $1.5{ }^{\circ} \mathrm{C}-2{ }^{\circ} \mathrm{C}$ stabilisation. Policy findings from the ADVANCE project, $\langle$ hal-01579189〉 HAL

Meinshausen $\mathrm{M}$ et al (2011) Emulating coupled atmosphere-ocean and carbon cycle models with a simpler model, MAGICC6: part I - model description and calibration. Atmos Chem Phys 11:1417-1456

Modak A et al. (2018) Does shortwave absorption by methane influence its effectiveness?. Climate Dynamics 51(9-10):3653-3672

Riahi K et al (2017) The shared socioeconomic pathways and their energy, land use, and greenhouse gas emissions implications: an overview. Glob Environ Chang

Rogelj J et al (2015) Impact of short-lived non-CO2 mitigation on carbon budgets for stabilizing global warming. Environ Res Lett 10

Saunois M et al (2016) The global methane budget 2000-2012. Earth Syst Sci Data 8:697-751

Smith S (2018) Forcing and temperature changes from methane and black carbon reduction scenarios, EMF30 special issue climatic change, forthcoming

Smith SJ et al (2012) Equivalence of greenhouse-gas emissions for peak temperature limits. Nat Clim Chang 2:535-538

Tavoni $\mathrm{M}$ et al (2014) Post-2020 climate agreements in the major economies assessed in the light of global models. Nat Clim Chang 5:119-126

UNFCCC (2015) Paris agreement. Decision 1/CP.17. http://unfccc.int/resource/docs/2015/cop21/eng/109r01.pdf, UNFCCC document FCCC/CP/2015/L.9/Rev.1

US-EPA (2013) United States Environmental Protection Agency (USEPA), Global mitigation of non-CO2 greenhouse gases: 2010-2030

Van Vuuren DP et al (2011) The representative concentration pathways: an overview. Clim Chang 109:5-31 
Publisher's note Springer Nature remains neutral with regard to jurisdictional claims in published maps and institutional affiliations.

\section{Affiliations}

Mathijs Harmsen ${ }^{1,2}$. Detlef P. van Vuuren ${ }^{1,2} \cdot$ Benjamin Leon Bodirsky ${ }^{3}$. Jean Chateau $^{4}$ • Olivier Durand-Lasserve ${ }^{4} \cdot$ Laurent Drouet $^{5}$ • Oliver Fricko ${ }^{6}$ - Shinichiro Fujimori $^{7,8}$ - David E. H. J. Gernaat ${ }^{1,2}$ - Tatsuya Hanaoka ${ }^{8}$ • Jérôme Hilaire ${ }^{3,9} \cdot$ Kimon $^{2}$ Keramidas $^{10}$ - Gunnar Luderer ${ }^{3}$ - Maria Cecilia P. Moura ${ }^{11}$ • Fuminori Sano ${ }^{12}$ • Steven J. Smith ${ }^{11} \cdot$ Kenichi Wada ${ }^{12}$

1 PBL Netherlands Environmental Assessment Agency, Bezuidenhoutseweg 30, 2594 AV The Hague, The Netherlands

2 Copernicus Institute for Sustainable Development, Utrecht University, Princetonlaan 8a, 3584 CB Utrecht, The Netherlands

3 Potsdam Institute for Climate Impact Research (PIK), POBox 6012 03, D-14412 Potsdam, Germany

4 OECD Environment Directorate, 2 rue André Pascal, 75116 Paris, France

5 RFF-CMCC European Institute on Economics and the Environment (EIEE), Centro Euro-Mediterraneo sui Cambiamenti Climatici, Via Bergogne 34, 20144 Milan, Italy

6 International Institute for Applied Systems Analysis, Schlossplatz-1, A-2361 Laxenburg, Austria

7 Department of Environmental Engineering, Kyoto University, Katsura-Campus, Nishikyo-ku, C1-3361 Kyoto, Japan

8 Center for Social\&Environmental Systems Research, National Institute for Environmental Studies (NIES), 16-2 Onogawa, Tsukuba, Ibaraki 305-8506, Japan

9 Mercator Research Institute on Global Commons and Climate Change (MCC), Torgauerstrasse 12, 10829 Berlin, Germany

10 European Commission - JRC, Edificio Expo, Calle Inca Garcilaso, 3, 41092 Sevilla, Spain

11 Joint Global Change Research Institute, Pacific Northwest National Laboratory, 5825 University Research Court, Suite 3500, College Park, MD 20740, USA

12 Research Institute of Innovative Technology for the Earth (RITE), 9-2, Kizugawadai, Kizugawa-Shi, Kyoto 619-0292, Japan 